\title{
Food buying habits of people who buy wine or beer: cross sectional study
}

Ditte Johansen, Karina Friis, Erik Skovenborg, Morten Grønbæk

\begin{abstract}
Objective To investigate whether people who buy wine buy healthier food items than those who buy beer.

Design Cross sectional study.

Setting Supermarkets in Denmark.

Data Information on number, type of item, and total charge from 3.5 million transactions over a period of six months. Results Wine buyers bought more olives, fruit and vegetables, poultry, cooking oil, and low fat cheese, milk, and meat than beer buyers. Beer buyers bought more ready cooked dishes, sugar, cold cuts, chips, pork, butter or margarine, sausages, lamb, and soft drinks than wine buyers.

Conclusions Wine buyers made more purchases of healthy food items than people who buy beer.
\end{abstract}

\section{Introduction}

The relation between total alcohol intake and mortality is $\mathrm{J}$ shaped,,$^{1-5}$ and the reduced risk of death associated with a small intake of alcohol may be due to the protective effect of ethanol against coronary heart disease. ${ }^{1-7}$ The differential effects of beer and wine on morbidity and mortality indicate that components other than ethanol may be important. ${ }^{8}$ Wine drinkers have a reduced risk of death from coronary heart disease and specific cancers. ${ }^{481011}$ Several components of wine have antithrombotic and anti-carcinogenic effects: polyphenolic substances inhibit platelet aggregation ${ }^{12}{ }^{13}$ and resveratrol inhibits the initiation, promotion, and progression of tumours. Usually, the relations between drinking beer, wine, and spirits and health outcomes are adjusted for confounding by sex, age, social class, and smoking; however, differences in beverage-specific drinking patterns or other risk factors could also affect the findings. ${ }^{9}$ Some studies have found that wine drinkers have a healthier diet than people who drink beer or spirits, and variation in diet associated with the preferred drink may explain why wine has an additional beneficial effect on health. ${ }^{14-16}$ However, self reporting may lead to under-reporting or over-reporting of diet and other lifestyle factors. ${ }^{17}{ }^{18}$ For example, the intake of certain food items may be exaggerated or understated according to people's wishes to meet health recommendations, and this misclassification may be associated with educational level, income, and preference for different alcoholic drinks.

To study whether people who buy wine also buy healthier food items and therefore have a healthier diet than those who buy beer, we investigated the relation between the purchase of beer and wine and various food items, using data from Danish supermarkets.

\section{Methods}

Data were taken from approximately 3.5 million transactions chosen at random from 98 outlets of two large Danish supermarket chains-16 Bilka and 82 Føtex supermarkets-over six months (from September 2002 to February 2003). Dansk Supermarked, which collects these data for inventory control, provided us with details of which items were bought, the number and price of the items, and the total charge for each customer's transaction. The data cannot be traced back to individual consumers.

Because spirits are bought in a separate section of the supermarkets and are not found on receipts for food, we could analyse only data relating to beer and wine. We categorised customers as "wine only," "beer only," "mixed," or "non-alcohol" buyers. Food items were divided into 40 categories (see table). All food items were dichotomised: 1 if a customer bought the item and 0 otherwise.

\section{Statistical analysis}

We used correspondence analysis and logistic regression to analyse the data. Correspondence analysis is a descriptive technique designed to analyse simple two way tables by measuring the association or correlation between the rows and columns; it measures the distances between the row and column points and presents the inter-relations of variables in two dimensional space. The distance is a measure of the correlation between any two points, and the analysis determines which category values are close together and which are far from each other; it may show unexpected dimensions and relations. These can be seen on a correspondence map, where the row and column points (categories) are plotted along the computed factor axes. Correspondence analysis aims to interpret the extracted dimensions, and it provides information similar to that produced by factor analysis, although it is a non-parametric method and thus makes no assumptions about distribution. The final goal of correspondence analysis is to obtain meaningful (subjective) interpretations of the two extracted dimensions. We used correspondence analysis to summarise the structure of data in high dimension food item space by projection on to low dimension subspaces, while losing as little information as possible, and to identify similarities in the food items bought by the different categories of alcohol buyers. In the first part of our analysis, we used correspondence analysis to investigate correlations between the four categories of alcohol buyers and also between the 40 food categories. We then carried out logistic regression analysis to estimate the size of the difference between beer and wine buyers with food categories as the dependent variable and the alcohol categories as the independent variable. Because of possible 
differences among customers buying different total numbers of food items, we analysed the data in strata of number of items bought $(<10,11-20,21-30,31-40$, and $>40)$.

\section{Results}

Customers who bought wine but not beer comprised 5.8\% of the total number of customers, and those who bought beer but not wine constituted $6.6 \%$ of the total number; $1.2 \%$ of customers bought both wine and beer. In general, customers who bought both beer and wine bought more food items and spent more money than other customers (table). A smaller proportion of beer buyers purchased fruit or vegetables, bread, poultry, milk, cereals, and sweets than other customers (table). A higher proportion of wine buyers than beer buyers bought all the food items, except for soft drinks, which were bought by a higher proportion of the beer buyers, probably because people who bought beer also bought fewer items and spent less than wine buyers (table). When we stratified the analyses according to the number of items bought and the total amount spent, the patterns were the same for all strata; therefore, the figures show the results of the merged strata.

Figure 1 shows the results of the correspondence analysis. Dimension 1 (vertical axis) explains $83 \%$ of the $\chi^{2}$ value and dimension 2 (horizontal axis) explains 17\%. Dimension 1 is linked to wine, beer, chips, soft drinks, veal, oil, and olives at one end and milk, cereals, cold cuts, and low fat products at the other end. Dimension 2 is linked to soft drinks, beer, lamb, chips, butter, sausages and pork at one end and olives, oil, veal, wine, and beef at the other end. The correspondence plot shows that beer buyers are more likely to buy chips, soft drinks, and lamb and that wine buyers are more likely to buy oil, olives, veal, and beef. Milk, bread, pasta, and cold cuts, which we interpreted subjectively as everyday purchases, were found at the low negative end of dimension 1, whereas chips, alcohol, veal, spices, and beef, which we interpreted as weekend shopping, were at the high positive end. Similarly, we interpreted dimension 2 as a Mediterranean diet (oil, wine, veal, low fat meat, and low fat cheese) at the low negative end and a traditional diet (beer, butter, sausages, and pork) at the high positive end.

Figure 2 shows the results of the logistic regression. Comparing wine and beer buyers, we found that beer buyers made fewer purchases of olives, fruit or vegetables, cooking oil, poultry, low fat milk, low fat cheese, and low fat meat than wine buyers and more purchases of soft drinks, lamb, sausages, butter or margarine, pork, chips, cold cuts, sugar, and ready cooked dishes.

\section{Discussion}

This study indicates that people who buy (and presumably drink) wine purchase a greater number of healthy food items than those who buy beer. Wine buyers bought more olives, fruit or vegetables, poultry, cooking oil, and low fat products than people who bought beer. Beer buyers bought more ready cooked dishes, sugar, cold cuts, chips, pork, butter, sausages, lamb, and soft drinks than people who bought wine. Wine buyers were more likely to buy Mediterranean food items, whereas beer buyers tended to buy traditional food items.

Customers who bought both beer and wine also bought the largest number of items. We stratified the analyses according to the number of items bought to oppose a possible bias, but similar patterns were found for all strata of number of items.
Percentages of the four categories of alcohol buyers who bought the 40 different food categories

\begin{tabular}{|c|c|c|c|c|}
\hline $\begin{array}{l}\text { Food } \\
\text { category }\end{array}$ & $\begin{array}{l}\text { Beer buyers } \\
(\mathrm{n}=230935)\end{array}$ & $\begin{array}{l}\text { Wine buyers } \\
(n=202992)\end{array}$ & $\begin{array}{c}\text { Beer and wine } \\
\text { buyers } \\
(n=42147)\end{array}$ & $\begin{array}{l}\text { Non-alcohol buyers } \\
(\mathrm{n}=3023550)\end{array}$ \\
\hline $\begin{array}{l}\text { Fruit or } \\
\text { vegetables }\end{array}$ & 38 & 51 & 58 & 42 \\
\hline Potatoes & 11 & 16 & 22 & 9 \\
\hline Bread & 32 & 37 & 44 & 35 \\
\hline Pasta & 3 & 4 & 5 & 3 \\
\hline Rice & 4 & 4 & 6 & 3 \\
\hline$\overline{B e e f}$ & 4 & 5 & 7 & 3 \\
\hline$\overline{\text { Veal }}$ & 0 & 1 & 1 & 0 \\
\hline Pork & 14 & 16 & 22 & 13 \\
\hline Poultry & 9 & 13 & 15 & 10 \\
\hline Lamb & $<0.5$ & $<0.5$ & $<0.5$ & $<0.5$ \\
\hline Fish & 14 & 17 & 23 & 11 \\
\hline $\begin{array}{r}\text { Low fat } \\
\text { meat }\end{array}$ & 2 & 2 & 2 & 2 \\
\hline Sausages & 4 & 4 & 6 & 4 \\
\hline Cold cuts & 23 & 25 & 32 & 23 \\
\hline $\begin{array}{l}\text { Low fat cold } \\
\text { cuts }\end{array}$ & 3 & 4 & 4 & 4 \\
\hline Milk & 44 & 51 & 60 & 48 \\
\hline Low fat milk & 13 & 16 & 17 & 16 \\
\hline Cheese & 21 & 28 & 35 & 21 \\
\hline $\begin{array}{l}\text { Low fat } \\
\text { cheese }\end{array}$ & 2 & 3 & 3 & 2 \\
\hline Eggs & 11 & 13 & 19 & 9 \\
\hline Flour & 5 & 6 & 9 & 5 \\
\hline Sugar & 4 & 5 & 7 & 4 \\
\hline $\begin{array}{l}\text { Butter or } \\
\text { margarine }\end{array}$ & 19 & 21 & 30 & 16 \\
\hline Oil & 2 & 3 & 4 & 1 \\
\hline Cereals & 6 & 8 & 9 & 7 \\
\hline Tea & 2 & 3 & 4 & 2 \\
\hline Coffee & 9 & 12 & 16 & 8 \\
\hline Jam & 5 & 6 & 9 & 4 \\
\hline Biscuits & 15 & 19 & 24 & 15 \\
\hline $\begin{array}{l}\text { Ready } \\
\text { cooked } \\
\text { dish }\end{array}$ & 21 & 23 & 29 & 21 \\
\hline $\begin{array}{l}\text { Tinned } \\
\text { goods }\end{array}$ & 13 & 16 & 23 & 11 \\
\hline Sauce & 9 & 12 & 16 & 8 \\
\hline $\begin{array}{r}\text { Ketchup or } \\
\text { mustard }\end{array}$ & 4 & 4 & 6 & 3 \\
\hline Olives & 1 & 2 & 4 & 1 \\
\hline Dried fruits & 9 & 12 & 16 & 8 \\
\hline Spices & 5 & 7 & 10 & 5 \\
\hline Chips & 11 & 11 & 20 & 7 \\
\hline Soft drinks & 34 & 27 & 47 & 23 \\
\hline Sweets & 29 & 34 & 41 & 34 \\
\hline Organic & 11 & 14 & 18 & 10 \\
\hline $\begin{array}{l}\text { Mean } \\
\text { number } \\
\text { of items }\end{array}$ & 15 & 17 & 26 & 11 \\
\hline Mean cost ${ }^{\star}$ & 216 & 301 & 458 & 129 \\
\hline
\end{tabular}

*Danish Kr: $1 \mathrm{Kr}=€ 0.13, £ 0.09, \$ 0.16$.

\section{Strengths and weaknesses of the study}

Self reports of alcohol intake are known to be unreliable. Survey participants may overestimate or underestimate their intake of certain nutrients and drinks, ${ }^{18}$ and the bias may differ according to the preferred drink. The risk of underestimation is reduced when questionnaires require detailed reports of alcohol consumption, ${ }^{18}$ although as the recall period increases the amount of alcohol that people report decreases. ${ }^{17}$ Our study was based on data from a random sample of approximately 3.5 mil- 


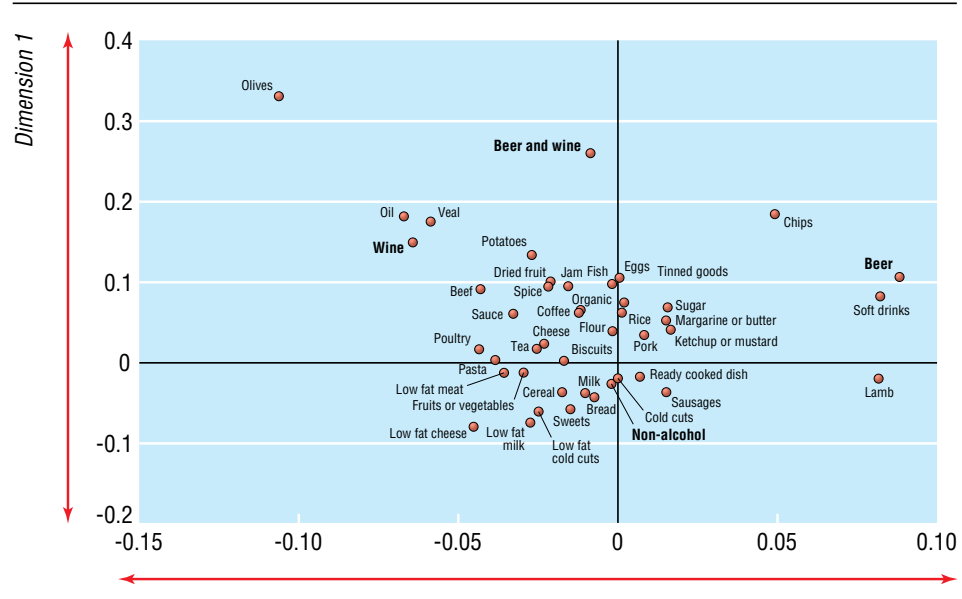

Dimension 2

Fig 1 Food items bought by wine and beer buyers. Food items that are highly correlated and more likely to be bought together are closer to each other

lion transactions from two supermarket chains in Denmark, and because we used information on what people buy, and presumably consume, rather than what they say they eat or drink, it was not flawed by under-reporting or over-reporting bias. The data obtained are precise figures and the study design (data collected over a long period of time) reduced seasonal variation.

Bilka and Føtex supermarkets are found in all parts of Denmark and have a broad product line, with regard to both food

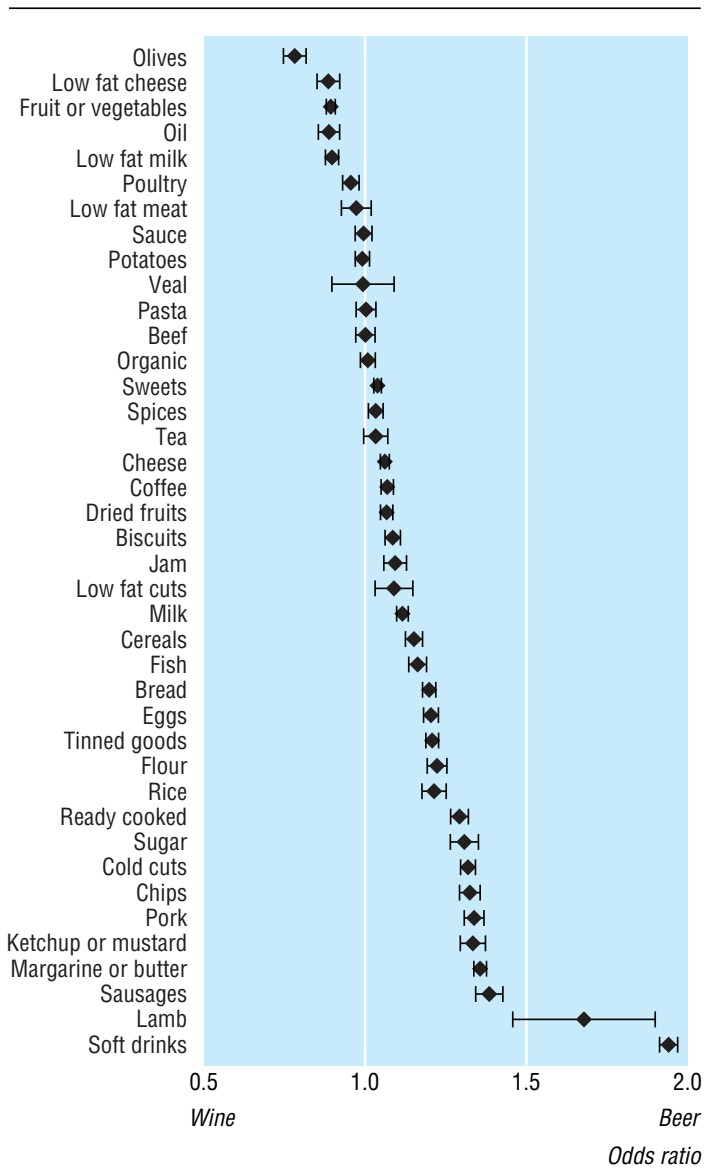

Fig 2 Likelihood of beer and wine buyers buying items of food. Items with an odds ratio lower than 1 are bought more often by wine buyers and items with an odds ratio higher than 1 are bought more often by beer buyers and non-food items, and their customers represent a broad section of the Danish population, although middle income families tend to be over-represented. Most of the beer (and probably most of the wine) traded in Denmark is sold in supermarkets and the customers studied represent a broad spectrum of the Danish population in all parts of Denmark. One drawback of this study is the lack of background information on the customers, such as age, sex, marital status, education, and income. Furthermore, we do not know if customers systematically buy certain items in the supermarket and others in specialist shops, but we assume that the purchases reflect what is eaten in the households. Another potential bias is that different people within the households may consume different food items. Customers who bought both beer and wine also bought the largest number of items, and wine and beer may be consumed by different individuals in the same household. However, we assume that most adult members of the households share drinking habits.

\section{Comparison with other studies}

Our results support findings from the United States, Denmark, and France showing that wine drinkers tend to eat fruit, vegetables, and fish and use cooking oil more often and saturated fat less often than those who prefer other alcoholic drinks. A Danish study has found that people who prefer wine have a higher intake of fruits, fish, vegetables, and salad and are more likely to use olive oil for cooking than those who prefer beer and spirits. ${ }^{16}$ A French study found that people who prefer wine eat more vegetables, fruit, bread, milk, cheese, and eggs and fewer potatoes than those who prefer beer. ${ }^{15}$ A study from the United States showed that people who drank wine had more servings of fruit and vegetables and fewer servings of red or fried meats, and that their diet contained less cholesterol, saturated fat, and alcohol and more fibre than people who drank other types of alcohol. ${ }^{14}$

Possible explanation of the health benefits of drinking wine The additional beneficial effect of drinking wine, rather than other alcoholic drinks, on mortality and morbidity from coronary heart disease and certain cancers may be due to specific substances in wine or to different characteristics of people who drink other types of alcohol. Drinking habits-how much alcohol is ingested, ${ }^{19}$ whether alcohol is consumed with food, ${ }^{20}$ and which type of alcohol is consumed ${ }^{14-16}$ - probably depend on social and cultural factors, lifestyle, and diet. Wine tends to be drunk with meals, in modest amounts, which may have metabolic advantages; in contrast, spirits are often 


\section{What is already known on this topic}

Drinking wine is associated with lower mortality than drinking beer and spirits

Self reports suggest that wine drinkers have healthier diets than beer or spirits drinkers

\section{What this study adds}

An objective measure of alcohol intake and dietary habits found that people who buy and presumably drink wine make more purchases of healthy food items than people who buy beer

consumed at times other than mealtime. ${ }^{20-22}$ In Denmark wine drinkers have a higher level of education, higher income, better psychological functioning, and better subjective health than people who do not drink wine. ${ }^{23}$ Similar results have been found in a Californian population: people who prefer wine tend to be educated, healthy, lean, young or middle aged women with a moderate alcohol intake, whereas those who prefer beer tend to be less educated, healthy young men with a higher alcohol intake. ${ }^{22}$ Thus, the influence of type of alcoholic drink on mortality could be due to insufficient adjustment for lifestyle factors such as diet, drinking patterns, smoking, physical activity, education, or income. ${ }^{23}$

The authors thank Dansk Supermarked for making the data available. Contributors: ES formulated the primary idea. DJ and MG initiated and coordinated the primary study hypothesis, discussed core ideas, designed the protocol, and wrote the paper. DJ collected and analysed the data. KF discussed the core ideas and participated in the interpretation of the data and the writing of the paper. ES discussed the core ideas and edited the paper. MG is guarantor.

Funding: The Health Insurance Foundation and the Danish Ministry of Health.

Competing interests: None declared.

Ethical approval: Not required because the data were anonymised.

1 Boffetta P, Garfinkel L. Alcohol drinking and mortality among men enrolled in an American Cancer Society prospective study. Epidemiology 1990;1:342-8.

2 Corrao G, Bagnardi V, Zambon A, Arico S. Exploring the dose-response relationship between alcohol consumption and the risk of several alcohol-related conditions: a meta-analysis. Addiction 1999;94:1551-73.

3 Fuchs C, Stampfer MJ, Colditz GA, Giovannucci EL, Manson J, Kawachi M, et al. Alcohol consumption and mortality among women. N Engl J Med 1995;332:1245-50.

4 Grønbæk M, Becker U, Johansen D, Gottschau A, Schnohr P, Hein HO, et al. Type of alcohol consumed and mortality from all causes, coronary heart disease, and cancer. Ann Intern Med 2000;133:411-9.
5 Klatsky AL, Armstrong MA, Friedman GD. Alcohol and mortality. Ann Intern Med 1992;117:646-54.

6 Mukamal K, Conigrave M, Mittleman M, Camargo C, Stampfer MJ, Willett WC, et al. Roles of drinking pattern and type of alcohol consumed in coronary heart disease in men. N Engl J Med 2003;348:109-18.

7 Wannamethee SG, Shaper A. Type of alcoholic drink and risk of major coronary heart disease events and all-cause mortality. Am J Public Health 1999;89:685-90.

8 Grønbæk M, Deis A, Sørensen TI, Becker U, Schnohr P, Jensen G. Mortality associated with moderate intakes of wine, beer, or spirits. BMJ 1995:310:1165-9.

9 Rimm EB, Klatsky AL, Grobbee D, Stampfer MJ. Review of moderate alcohol consumption and reduced risk of coronary heart disease: is the effect due to beer, wine or spirits? BMJ 1996;312:731-6.

10 Klatsky AL, Armstrong MA. Alcoholic beverage choice and risk of coronary artery disease mortality: do red wine drinkers fare best? Am J Cardiol 1993;71:467-9.

11 Klatsky AL, Friedman GD, Armstrong MA, Kipp H. Wine, liquor, beer and mortality. Am J Epidemiol 2003;158:585-95.

12 Pace-Asciak C, Hahn S, Diamandis E, Soleas G, Goldberg D. The red wine phenolics trans-resveratrol and quecetin block human platelet aggregation and eicosanoid synthesis: implications for protection against coronary heart disease. Clin Chim Acta 1995;235:207-19.

13 Renaud S, de Lorgeril M. Wine, alcohol, platelets, and the French paradox for coronary heart disease. Lancet 1992;339:1523-6.

14 Barefoot JC, Grønbæk M, Feaganes JR, McPherson RS, Williams RB, Siegler IC. Alcoholic beverage preference, diet, and health habits in the UNC alumni heart study. AmJ Clin Nutr 2002;76:466-72.

15 Ruidavets JB, Bataille V, Dallongeville J, Simon C, Bingham A, Amouyel P, et al. Alcohol intake and diet in France, the prominent role of lifestyle. Eur Heart J 2004;25:1153-62.

16 Tjønneland A, Grønbæk M, Stripp C, Overvad K. Wine intake and diet in a random sample of 48763 Danish men and women. Am J Clin Nutr 1999;69:49-54.

17 Ekholm O. Influence of the recall period on self-reported alcohol intake. Eur J Clin Nutr 2004;58:60-3.

18 Grønbæk M,.Heitmann B. Validity of self-reported intakes of wine, beer and spirits in population studies. Eur J Clin Nutri 1996;50:487-90.

19 Kesse E, Clavel-Chapelon F, Slimani N, van Liere M, E3N Group. Do eating habits differ according to alchohol consumption? Results of a study of the French cohort of the European prospective investigation into cancer and nutrition (E3N-EPIC). Am J Clin Nutr 2001;74:322-7.

20 Trevisan M, Dorn J, Falkner K, Russell M, Ram M, Muti P, et al. Drinking pattern and risk of non-fatal myocardial infarction: a population-based case-control study. Addiction 2003;99:313-22.

21 Gaziano J, Buring J. Alcohol intake, lipids and risks of myocardial infarction. Novatis Found Symp 1998;216:86-95.

22 Klatsky AL, Armstrong MA, Kipp H. Correlates of alcoholic beverage preference: traits of persons who choose wine, liquor or beer. Br J Addict 1990;85:1279-89.

23 Grønbæk M, Mortensen E, Mygind K, Andersen A, Becker U, Gluud C, et al. Beer, wine, Grønbæk M, Mortensen E, Mygind K, Andersen A, Becker U, Gluud C, et al B
spirits and subjective health.J Epidemiol Community Health 1999;53:721-4.

24 Mortensen E, Jensen H, Sanders S, Reinisch J. Better psychological functioning and higher social status may largely explain the apparent health benefits of wine. Arch Intern Med 2001;161:1844-8.

(Accepted 14 November 2005)

doi $10.1136 /$ bmj. 38694.568981 .80

National Institute of Public Health, Øster Farimagsgade 5 A, DK-1399

Copenhagen K, Denmark

Ditte Johansen statistician

Karina Friis research assistant

Morten Grønbæk professor

Knebel, Denmark

Erik Skovenborg general practitioner

Correspondence to: M Grønbæk mg@niph.dk 